\title{
"Clipless" Cholecystectomy: Evolution Marches On, Even for Lap Chole
}

\author{
Lee L. Swanstrom
}

Published online: 15 February 2011

(c) Société Internationale de Chirurgie 2011

It is nearly a quarter century since laparoscopic cholecystectomy was introduced to surgeons and forever changed how we think about surgery. Laparoscopy changed not only how we accessed the gallbladder but almost every single element of how the surgery had been done for over 100 years, i.e., how the gallbladder was exposed and retracted, how Calot's triangle was visualized, performing retrograde dissection versus antegrade, and the need for and frequency of cholangiography. One thing that did not change, however, was the method of ligating the cystic duct and artery. At least in the developed world, by the mid-1980s titanium clips had largely replaced suture ligation, which more often than not was performed only to demonstrate to residents and medical students how things were once done or to test their knot-tying abilities [1]. In fact, it was exclusively the development of the laparoscopic clip applier that made possible the widespread and rapid adoption of the procedure, as the ability to intracorporeally ligate the duct and artery was unthinkable to all but a handful of the most accomplished masters of laparoscopy of that time.

The article by Kavlakoglu et al. [2] which contributes another study to the growing body of literature regarding the safety and efficacy of tissue welding to close the cystic duct during cholecystectomy, hints at the final change in the old paradigm of cholecystectomy. While 25 years into it may imply that a change is unneeded, the current "old" method of clipping the duct and artery is not a perfect solution. Titanium clips have been known to migrate into adjacent structures, cause strictures due to a foreign body

L. L. Swanstrom ( $\square)$

GI and Minimally Invasive Surgery Division,

The Oregon Clinic, 1040 NW 22nd Avenue,

Suite 560, Portland, OR 97210, USA

e-mail: 1swanstrom@aol.com response, serve as a nidus for stone formation, and occasionally fall off and result in substantial morbidity [3]. There is also the element of cost: while reusable clip appliers are available, by far the majority of clips are applied with fairly expensive disposable devices. And there is the added cost of lost efficiency caused by yet another instrument change. Thus, one might propose that a more perfect cholecystectomy would be where the assistant retracts and exposes the gallbladder and the surgeon inserts two instruments, a grasper in one hand and an (relatively inexpensive) energy source in the other; dissects, divides, and resects the gallbladder without an instrument change; and then at the end withdraws the gallbladder and the instruments, leaving behind a dry and secure field with no foreign bodies.

Obviously, the most critical issue at hand is the security of the duct closure. In the mid-1990s, when new laparoscopic energy sources (ultrasonic and bipolar) were being rapidly adopted and widely deployed, a seminal report by Mathews et al. [4] reported high leak rates for both ultrasonic and bipolar devices in an animal model. This pretty much erased interest in using these devices for a "clipless cholecystectomy" until recently, when a large number of reports of clinical and experimental cystic duct sealing have been reported. Unlike the earlier report, the majority of recent studies, including that by Kavlakoglu et al. [2], indicate that it is indeed possible to safely use bipolar or ultrasonic energy to seal the duct/artery [5-9]. The reason for this change in recommendation from the Matthews et al. article is not totally clear; perhaps the pig is a poor model or maybe the technology has improved over the last decade.

It is important that the energy source be usable for the rest of the gallbladder dissection because there is little advantage in simply replacing an expensive clip applier 
with an equally or more expensive "duct sealer" that could not be used for the rest of the dissection. While the Kavlakoglu et al. article does not address the cost and universal utility of this particular instrument, it certainly contributes to the move toward a clipless cholecystectomy which will be an important last step in the "lap chole" revolution.

\section{References}

1. Cogliano FD, Marcello DE Jr (1972) Use of hemoclips in cholecystectomy. Arch Surg 104(3):351-352

2. Kavlakoglu B, Pekcici R, Oral S (2011) Clipless cholecystectomy: which sealer should be used? World J Surg 35. doi:10.1007/ s00268-010-0819-3

3. Herline AJ, Fisk JM, Debelak JP et al (1998) Surgical clips: a cause of late recurrent gallstones. Am Surg 64(9):845-848
4. Matthews BD, Pratt BL, Backus CL et al (2001) Effectiveness of the ultrasonic coagulating shears, LigaSure vessel sealer, and surgical clip application in biliary surgery: a comparative analysis. Am Surg 67(9):901-906

5. Schulze S, Damgaard B, Jorgensen LN et al (2010) Cystic duct closure by sealing with bipolar electrocoagulation. JSLS 14(1):20-22

6. Carvalho GL, Silva FW, Silva JS et al (2009) Needlescopic clipless cholecystectomy as an efficient, safe, and cost-effective alternative with diminutive scars: the first 1000 cases. Surg Laparosc Endosc Percutan Tech 19(5):368-372

7. Kandil T, El Nakeeb A, El Hefnawy E (2010) Comparative study between clipless laparoscopic cholecystectomy by harmonic scalpel versus conventional method: a prospective randomized study. J Gastrointest Surg 14(2):323-328

8. Kavlakoglu B, Pekcici R, Oral S (2010) Verification of clipless closure of cystic duct by harmonic scalpel. J Laparoendosc Adv Surg Tech A 20(7):591-595

9. Gelmini R, Franzoni C, Zona S et al (2010) Laparoscopic cholecystectomy with Harmonic scalpel. JSLS 14(1):14-19 